EPJ Web of Conferences I14,02110 (2016)

DOI: $10.1051 /$ epjconf/201611402110

(C) Owned by the authors, published by EDP Sciences, 2016

\title{
Investigation of possible causes of the additional torque on the yacht's rudder
}

\author{
Soukup Lubomir ${ }^{1, a}$, Stigler Jaroslav ${ }^{1}$, and Kharicha Abdellah ${ }^{2}$ \\ ${ }^{1}$ Victor Kaplan Dept. of Fluid Engineering, Faculty of Mechanical Engineering, Brno University of Technology, Czech Republic \\ ${ }^{2}$ Dept. of Simulation and Modelling of Metallurgical Process, Montanuniversität Leoben, Austria
}

\begin{abstract}
The present article deals with investigation of possible causes of the additional torque on the yacht's rudder. One of the most important aspect for design of yachts are the symmetric conditions of all parts, which are located under water level and concentricity of the ship's screw, rudder and keel relative to the hull. These symmetric and concentricity conditions have a major impact on the resulting dynamic properties of the ships. They have either substantial impact on the overall efficiency of installed engine and ship's screw. As the result of poorly designed above mentioned parts, there can be an unsolicited additional torque on the yacht's rudder and higher consumption of the fuel. Last but not least of these problems leads to poor controllability and discomfort within steering. This article is focused on the investigation of possible causes of the additional torque on the yacht's rudder.
\end{abstract}

\section{Introduction}

Several studies have been carried out on the problematic of the symmetric shapes of rudders or the shapes of wings in connection with other parts as are a hull and keel of the yacht or a ship's screw shaft. Some of them were conducted by using an analytical approaches, others by using experiments and in some of them were used numerical simulations as for example CFD or CFX. German physicist Ludwig Prandtl (1875 - 1935) was one of the founders of the modern aerodynamics and the theory of boundary layer. It is possible to find many theories in Prandtl's publications including a flow around symmetric and asymmetric profiles. The foundations aerodynamic theories are described for example in [1] or in [2]. There are other researches of aerodynamic problems around different profiles made by Munson and collective [3] and research of CFD simulation of propeller and rudder performance when using additional thrust fins [4]. Other research was performed about the flow around the rudder and hull of sailing yacht, where the results from CFD simulation are compared with experiments [5]. An aerodynamic analysis was conducted for special yacht, where is described a comparison between experiment in towing tank and CFD results which considered free surface waves [6].

Yachts are generally divided into two groups. First group are yachts without combustion engine (often sport's yachts) and second group are yachts with combination of the sails and a combustion engine, which can be used in case of needs to sail a yacht regardless of the wind. In this work is described the yacht having the combination of combustion engine and sails. There are very important steps for design of yachts, especially the symmetric conditions of all parts which are located under water level and concentricity of the ship's screw, rudder and keel relative to the hull. If one of these parts is not symmetric or not in concentricity, it can among other occur an additional unsolicited torque acted on the rudder when the crew uses the combustion engine to sail the yacht. This work describes a yacht which has one above described problem or combination of these problems, namely when the crew uses the engine to sail the yacht at the specific speed, the maximal additional torque acted on the rudder is $T_{r}=218.16 \mathrm{~N} \cdot \mathrm{m}$. As a consequence of this additional torque, there is torque acting on steering wheel $T_{s w}=31.88 \mathrm{~N} \cdot \mathrm{m}$. This value means additional weight $5 \mathrm{~kg}$ on the diameter of the steering wheel.

For all above mentioned parts of the yacht, it is very difficult to find out the symmetric and concentricity conditions directly on the yacht via some measurement. There is only way to find the exact shape, symmetric conditions and concentricity of all above described parts, when the yacht would be picked up from the water and it would be made 3-D scan or very precise measurement of all problematic parts, which are located under water level. However this process is very expensive and timeconsuming. Experimental measurements is also almost unfeasible since to measure all the necessary parameters (water flow, velocity and pressure) directly on the sailing yacht is almost impossible, since the measurement can be

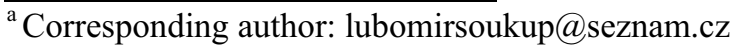


affected by many factors in case of natural conditions on the open sea.

An alternative way is the numerical simulation of problematic cases. The possible impacts of poorly designed parts will therefore be determined by numerical simulation in program Ansys Fluent. An approximate shape of rudder, keel and hull was obtained from the technical documentation of the yacht. There were provided also the data of the measured torque on the steering wheel and transmission ratio of the rudder system.

\section{Possible problems of the yacht and technical parameters}

If the yacht sails without using the combustion engine then the additional torque on rudder has almost zero value. It is possible to make decision that the additional torque has been caused only by parts related to the ship's screw and rudder. The most likely problems of this examined yacht are therefore:

- Asymmetric shape of the rudder

- Misalignment of the rudder relative to the hull (concentricity of the ship's shaft screw relative to the hull)

- Combination of misalignment of the rudder relative to the hull and deviation of the ship's shaft screw

Technical parameters were obtained or estimated from the technical documentation. Since the technical documentation was incomplete particularly with regard to the dimensions, the unknown proportions were estimated from the ratio of pixels and known dimensions in technical drawings. Some of the dimensions were completely unknown so in these cases were used the data measured and provided by the owner of the yacht. The ship's screw in real case is about $1000 \mathrm{~mm}$ behind the hull. With regard to this distance it was suggested to simulate the water stream from ship's screw as a stream flowing out from a "tunnel". Although this suggestion is not correct, we consider this simplification as negligible with respect to 2-D approach of the entire problem. Important data which were used in the following simulations are:

- Diameter of the ship's screw $D_{\text {screw }}=508 \mathrm{~mm}$

- Speed of yacht $v_{y a c h t}=5.8$ knots $=3 \mathrm{~m} / \mathrm{s}$

Other physical values used for simulation

- Density of the sea water $\rho_{w}=1024 \mathrm{~kg} / \mathrm{m}^{3}$

- Density of the air $\rho_{\text {air }}=1.23 \mathrm{~kg} / \mathrm{m}^{3}$

- Kinematic viscosity of the sea water $v_{w}=1.15$. $10^{-6} \mathrm{~m}^{2} / \mathrm{s}$

\section{Measured values of the torque on the rudder}

Two sets of torque measurements on the rudder were provided by the yacht owner. Each set was performed under different conditions. First measurement was performed for a headwind $v_{1 \text { hwind }}=3-5$ knots. (Tab 1).

The second set was performed for the headwind v2 hwind $=5-7$ knots (Tab 2). The dependences of torque on the yacht velocity for both cases are also drawn in Figure 1.

Tab 1. Values of torque for headwind 3-5 kn

\begin{tabular}{|c|c|c|c|c|c|}
\hline \multirow{2}{*}{$\begin{array}{l}\text { Revol } \\
\text { utions } \\
{\left[\min ^{-}\right.} \\
\left.{ }^{1}\right]\end{array}$} & \multicolumn{2}{|c|}{$\begin{array}{l}\text { Velocity of } \\
\text { the yacht }\end{array}$} & \multirow{2}{*}{$\begin{array}{c}\text { Traction on the } \\
\text { steering wheel } \\
{[\mathrm{kg}]}\end{array}$} & \multirow{2}{*}{$\begin{array}{c}\mathrm{T}_{\mathrm{kk}} \\
{[\mathrm{Nm}]}\end{array}$} & \multirow{2}{*}{$\begin{array}{c}\mathrm{T}_{\mathrm{k}} \\
{[\mathrm{Nm}]}\end{array}$} \\
\hline & {$[\mathrm{kn}]$} & $\begin{array}{c}{\left[\mathrm{m} . \mathrm{s}^{-}\right.} \\
1]\end{array}$ & & & \\
\hline 750 & 2,1 & 1,167 & 0 & 0 & 0 \\
\hline 1000 & 3,5 & 1,944 & 1 & 6,38 & 43,72 \\
\hline 1400 & 4,9 & 2,722 & 1,3 & 8,29 & 56,84 \\
\hline 1800 & 5,9 & 3,278 & 2 & 12,75 & 87,45 \\
\hline 2200 & 6,8 & 3,778 & 3 & 19,13 & 131,17 \\
\hline 2600 & 7,7 & 4,278 & 4 & 25,51 & 174,9 \\
\hline
\end{tabular}

Tab 2. Values of torque for headwind 5-7 kn

\begin{tabular}{|c|c|c|c|c|c||}
\hline $\begin{array}{c}\text { Revolut } \\
\text { ions } \\
{\left[\mathrm{min}^{-1}\right]}\end{array}$ & \multicolumn{2}{|c|}{$\begin{array}{c}\text { Velocity of } \\
\text { the yacht }\end{array}$} & $\begin{array}{c}\text { Traction on the } \\
\text { steering wheel } \\
{[\mathrm{kg}]}\end{array}$ & $\mathrm{T}_{\mathrm{kk}}$ & $\mathrm{T}_{\mathrm{k}}$ \\
\cline { 2 - 4 }$[\mathrm{Nm}]$ & {$[\mathrm{Nm}]$} \\
\hline \hline 1000 & 2,6 & 1,444 & 0,2 & 1,28 & 8,74 \\
\hline 1400 & 4,1 & 2,278 & 1 & 6,38 & 43,7 \\
\hline 1800 & 5 & 2,778 & 1,8 & 11,48 & 78,70 \\
\hline 2200 & 6 & 3,333 & 2,3 & 14,67 & 131,1 \\
\hline 2600 & 6,9 & 3,833 & 3 & 19,13 & 131,1 \\
\hline 3100 & 7,7 & 4,278 & 5 & 31,88 & 218,6 \\
\hline
\end{tabular}

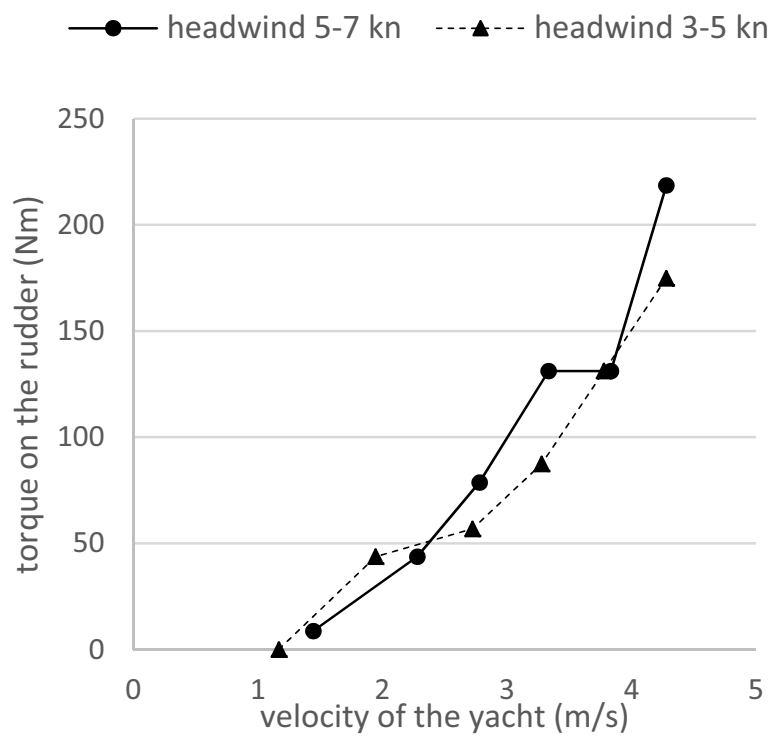

Figure 1. Graph of the additional torque on the rudder shaft

\section{Solving of problem by software and solving process}

The increasing of torque during the acceleration of the yacht can be determined numerically. Since there were no 
exact dimensions of some parts of the yacht, the main aim of the numerical simulation cannot be to determine the exact torque acting on the rudder of yacht, but to determine whether is possible to obtain additional torque with similar values or with similar trends which were measured on the rudder in real case. A geometry of the yacht was created in software Gambit. Numerical simulation was done by software Ansys Fluent. This software is based on the finite volume method.

The solving process was completely solved in 2-D dimension with respect to impossibility to create the exact 3-D model from the provided technical documentation and drawings. This process was divided into three separate parts namely: simulation of the asymmetric shape of the rudder, simulation of misalignment of the rudder relative to the hull (concentricity of the ship's screw shaft relative to the hull) and last simulation was performed for misalignment of the rudder relative to the hull considering the deviation of the ship's shaft screw relative to the hull.

The asymmetric geometry is based on a rough measurement of the real rudder on the yacht. Since the measurement cannot be considered as very accurate with regard to the fact that the measurement was carried out under water surface. It was suggested to perform the simulation with a small deviation $5 \mathrm{~mm}$ in the location of the largest width of the rudder (Figure 2), since it was found out with certainty that the least measured deviation was $5 \mathrm{~mm}$.

All cases of misalignment and deviation in rudder shaft have initial position as in ideal case, it means misalignment $0 \mathrm{~mm}$ and deviation $0^{\circ}$. The step in misalignment is $10 \mathrm{~mm}$ and a maximum misalignment of rudder is $40 \mathrm{~mm}$. The deviation of the ship's shaft screw is $3^{\circ}$ for all cases of misalignment. For all 2-D simulations was used the top cross-section geometry from the location of the ship's screw shaft as is depicted in Figure 3 and Figure 5.

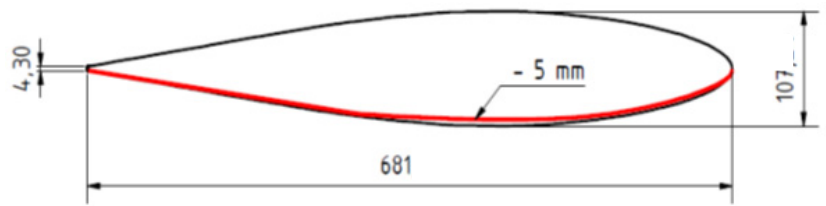

Figure 2. Asymmetric geometry of the rudder in $\mathrm{mm}$ (top crosssection)

\section{Mathematical simulation}

Computational meshes for mathematical simulations were made in software Gambit. It was necessary to prepare the mesh of asymmetric rudder (the shape of the asymmetric rudder is in Figure 2), five meshes for the misalignment of the rudder relative to the hull (concentricity of the ship's shaft screw relative to the hull - Figure 3) and five meshes for the misalignment of the rudder relative to the hull considering deviation of the ship's shaft screw relative to the hull (Figure 4).

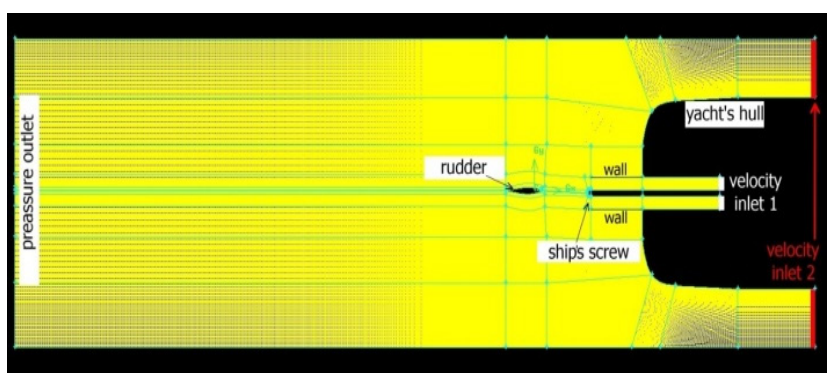

Figure 3. $40 \mathrm{~mm}$ misalignment of the rudder relative to the hull, the hull and ship's screw shaft are concentric (top crosssection)

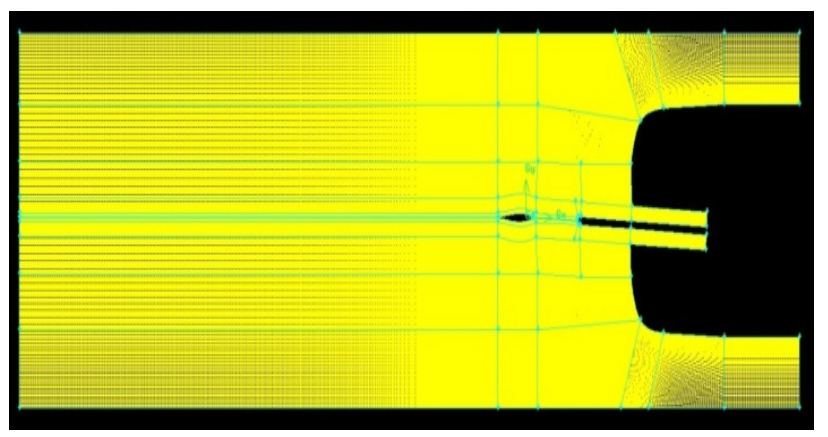

Figure 4. $40 \mathrm{~mm}$ misalignment of the rudder relative to the hull, deviation of the ship's screw shaft relative to the hull (top crosssection)

Numbers of cells for each mesh is 490 thousand and all meshes were made by quad cells and a map type. In meshing processes the qualitiy as EquiSize skew were checked, the worst element had a value of 0.62 . Difficulties of whole meshing were related to a fine meshing process in area behind the hull and around the rudder. The boundary conditions were set as velocity inlet on all inlets and as pressure outlet on all outlets - the boundary conditions are displayed in the Figure 3. There are two velocity inlets with different velocity values. Velocity inlet $2\left(v i_{2}\right)$ represents the water stream from the water flowing around the hull and velocity inlet $1\left(v i_{1}\right)$ represents the water flow from the ship's screw. All simulations were conducted with the same velocity at velocity inlet $2 v i_{2}=3 \mathrm{~m} / \mathrm{s}$ (this is an average velocity of the sailing yacht in relation to see) and with different velocity at velocity inlet $1 v i_{1}=0,5,10$ and $15 \mathrm{~m} / \mathrm{s}$. The progress of velocity on velocity inlet 1 was specific for case considering asymmetric rudder shape as is described in a Chapter 6 . The maximal velocity of the water stream from the ship's screw can be approximately $15-20 \mathrm{~m} / \mathrm{s}$ (this information was obtained from the producer of ship's screw website for engine with output $75 \mathrm{~kW}$ by which is the yacht fitted).

In program Ansys Fluent were simulated almost 60 different cases. It was elected turbulent K- $\varepsilon$ model with non-equilibrium wall function. The values of Wall $\mathrm{Y}^{+}$ were checked to ensure the correct results. The torque was evaluated directly from the Ansys Fluent for cases of steady flow and for cases of unsteady flow was the torque evaluated from the time-averaged maximum values of torque coefficient. The torque was related to the shaft of 
the rudder. The height of the rudder was chosen to be a partial height $h=508 \mathrm{~mm}$ to have possibility to evaluate the particularly impact of the fluid flow from the combustion engine, respectively from the ship's screw. This height was implemented into simulation only for expressions of the value of the additional torque from 2-D dimension. This assumption can be considered as assumption close to real case since the rudder has almost the same top cross-section's shape in the area behind the ship's screw [7],[8].

\section{Results}

With regard to the many numerical simulations, it was decided to make an evaluation for each problem separately. At first, partial results were evaluated for asymmetric rudder shape. It is clear from the graph in the Figure 5 that for the velocities from 0 to approximately $18 \mathrm{~m} / \mathrm{s}$ the additional torque on the rudder's shaft is negligible however the additional torque increases significantly for the velocities near to $18-20 \mathrm{~m} / \mathrm{s}$. There were made more simulations in this case in order to acquire necessary velocity of the water stream form ship's screw to find a region of increment of the additional torque. Figures 6 and 7 show the velocity and pressure contours in an area around the rudder.

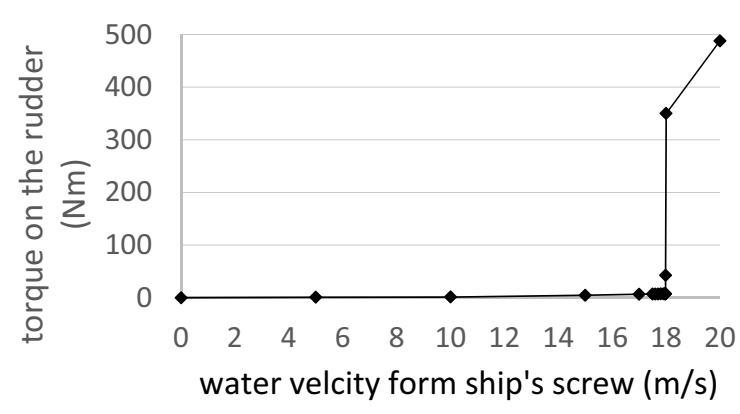

Figure 5. Graph of additional torque on the asymmetric rudder

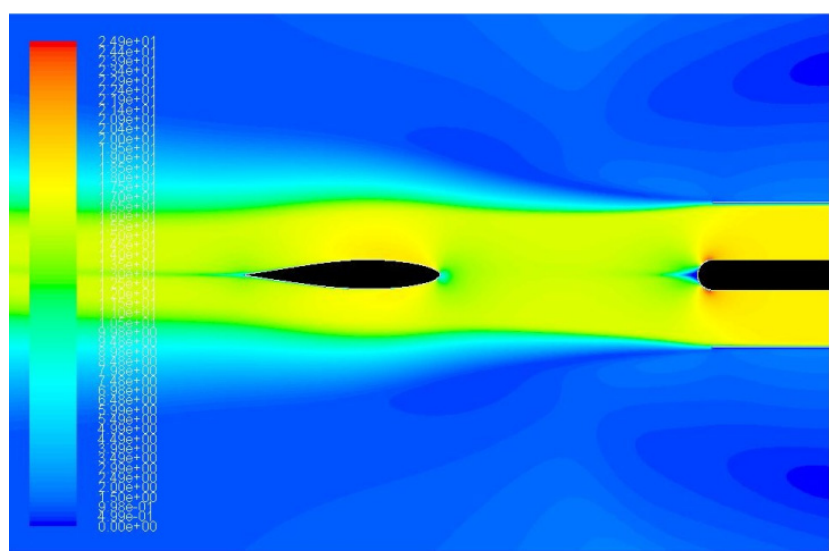

Figure 6. Contours of asymmetric rudder - velocity field

Further partial results were evaluated for the case of the misalignment of the rudder relative to the hull (considering concentricity of the ship's shaft screw relative to the hull).

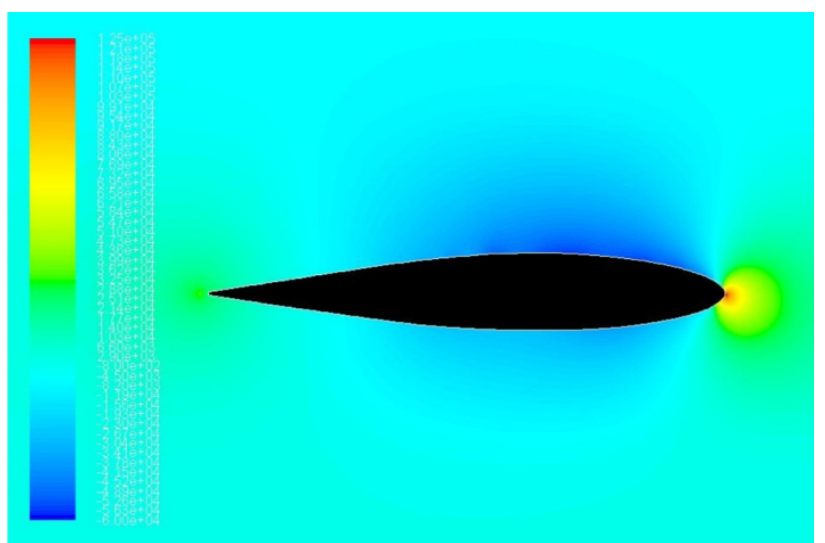

Figure 7. Contours of asymmetric rudder - static pressure field

It is evident in the graph in Figure 8 that the additional torque on the rudder shaft is increasing slowly and from the velocity 10 to $15 \mathrm{~m} / \mathrm{s}$ the torque increases significantly. It was not necessary to continue with simulation to the velocity $20 \mathrm{~m} / \mathrm{s}$, since the value of the maximum torque is in all cases higher or very close to the value of the maximum torque from the measured data in the graph in Figure 1. The fields of the velocity and pressure contours are depicted in Figures 9 and 10.

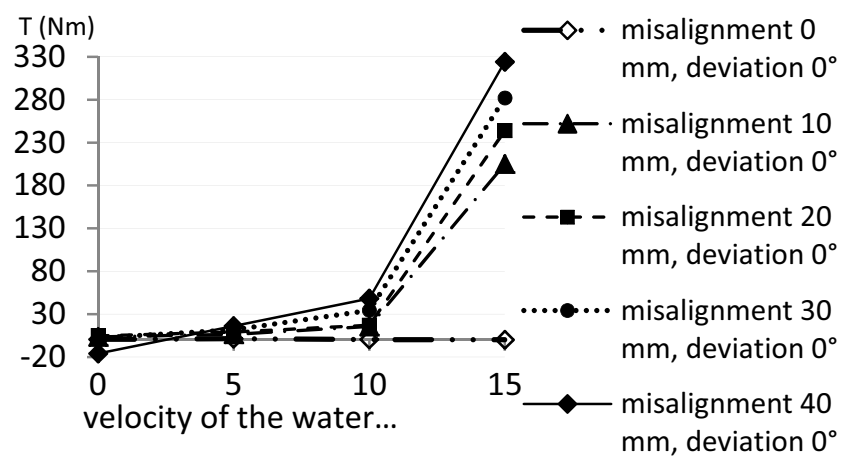

Figure 8. Additional torque for misalignment of the rudder relative to the hull considering concentricity of the ship's screw shaft relative to the hull

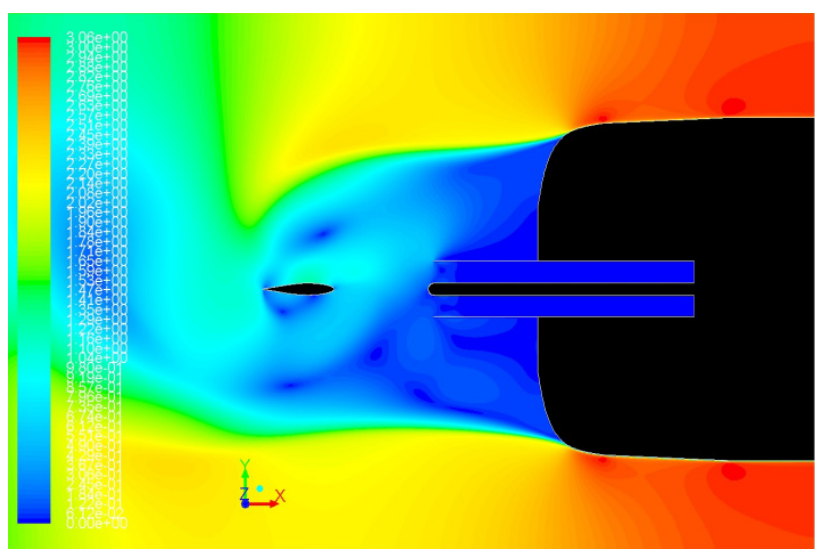

Figure 9. Contours of zero misalignment - velocity field 


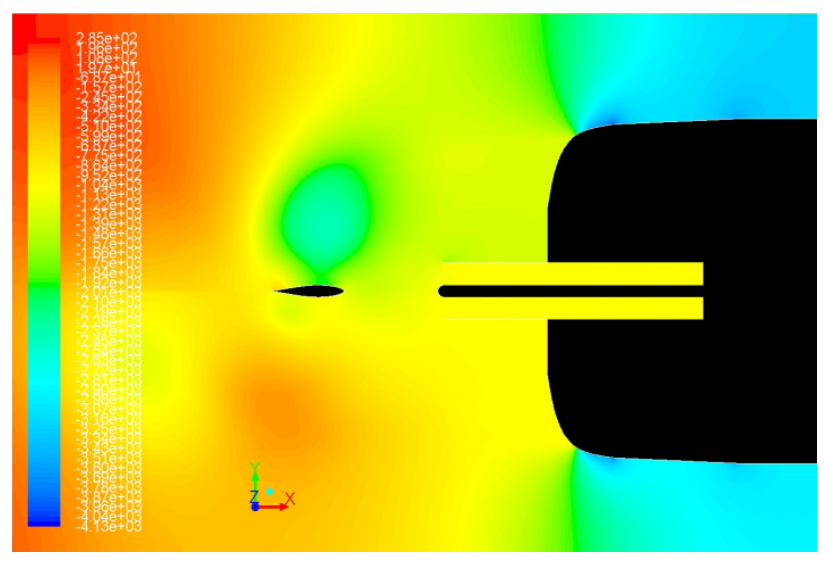

Figure 10. Contours of zero misalignment - static pressure field

Last set of the results were evaluated for the misalignment of the rudder relative to the hull considering deviation angle $3^{\circ}$ of the ship's screw shaft relative to the hull. It is obvious from the graph in Figure 11 that the additional torque on the rudder shaft has negligible or negative value for velocities from 0 to 10 $\mathrm{m} / \mathrm{s}$ and for velocities from 10 to $15 \mathrm{~m} / \mathrm{s}$ the torque increases (instead of case of misalignment $0 \mathrm{~mm}$ and deviation $3^{\circ}$ ). It is apparent that this trend does not respond to the trend from the graph in Figure 1 and therefore it was not necessary to continue in this simulation to the velocity $20 \mathrm{~m} / \mathrm{s}$.

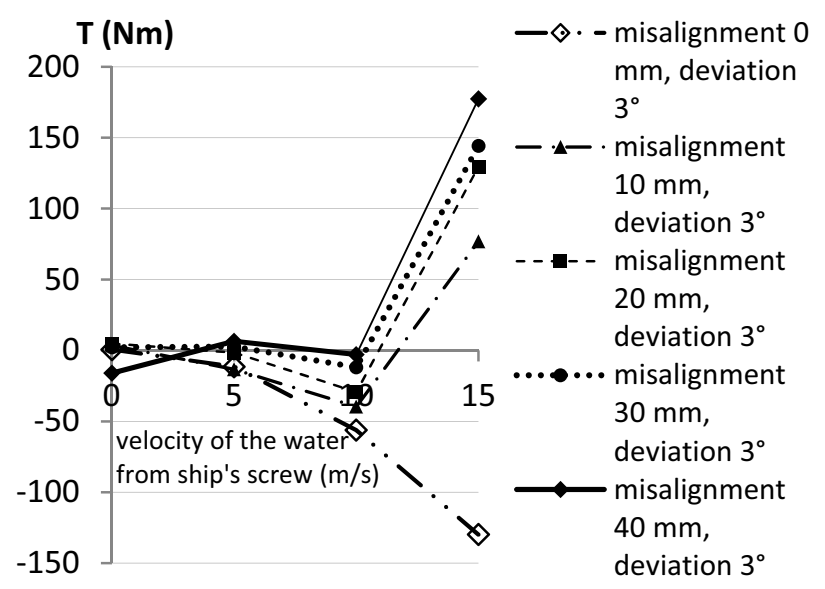

Figure 11. Additional torque for misalignment of the rudder relative to the hull considering deviation of the ship's shaft screw relative to the hull

\section{Assessment of the results and comparison with measured data}

The direct comparison of the measured and simulated data is not possible since there is no dependence in measured data on the velocity of the water flow from ship's screw. The assessment must be performed from a trend of the additional torque. As it is shown in the graph in Figure 11 the trend for solution of the additional torque for misalignment of the rudder relative to the hull considering deviation of the ship's shaft screw relative to the hull does not correspond to measured data. From this fact it can be argued that this problematic is the least likely problem from all three cases.

The most similar results to measured data are represented by solution of additional torque for the misalignment of the rudder relative to the hull (concentricity of the ship's screw shaft relative to the hull). The trend in this case is the most similar trend to the measured data. However, it should be taken into account either the set of results of asymmetric shape of the rudder. In both cases (misalignment of rudder and asymmetric shape of rudder) is the fundamental reason of additional torque a non-uniform velocity field around the rudder. This non-uniform velocity filed causes action of buoyancy force on the rudder. If the asymmetric shape of the rudder has higher deviation then it is sure that the additional torque will grow rapidly for lower velocities and the trend of the torque would have more similar progress to the measured data.

\section{Proposed changes and their effects}

First proposed change is to remove the rudder from the yacht and perform a precise measurement of the potential deviation from the ideal symmetric rudder shape. If the first adjustment shows that the ruder is asymmetric, then it would be necessary to use special sealants which have a long durability in seawater and modify the shape of the rudder to the accurate symmetric shape. If the first modification shows that the rudder has symmetric shape then it has to be performed the exact measurement of the concentricity of the rudder and ship's screw shaft relatively to the hull.

Effect of first proposed change was fortunately successful since there was found out a larger deviation than $5 \mathrm{~mm}$ in the symmetry of the yacht's rudder. After precise modification of the shape of the rudder to precise symmetric shape the additional torque decreased to the negligible value.

\section{Conclusion}

At the beginning of this article the problem of the yacht is described. There are three possible cases, which may constitute a reason of the additional torque on the rudder shaft namely:

- Asymmetric shape of the rudder

- Misalignment of the rudder relative to the hull

- Deviation of the ship's shaft screw relative to the hull.

It would be possible to make 3-D scan of all parts located under water level to find out the exact geometry of the yacht, or there could be performed the exact measurement directly on the yacht. However both these methods are very time-consuming and expensive. The mathematic simulation can be made as a further method to find out the reason of the additional torque.

Subsequently the simulation mesh was created in the software Gambit and the quality of all meshes were checked (Equi Size Skew worst element had quality 0.62 ). The number of cells was 490 thousand for all meshes. A turbulent model was elected as K- $\varepsilon$ with nonequilibrium wall function. Boundary conditions were set 
as velocity inlet on all inlets and pressure outlet on all outlets for all simulations.

Then the results obtained from the mathematical simulations were presented. It was impossible to perform the direct comparison of simulation results with the measured data since the measured data has no dependence on the velocity of the water flow from the ship's screw. The trend of additional torque was used as a comparative benchmark to decide which case of simulated problem could be the reason of the additional torque. The comparison of results shows that the additional torque could occur by the misalignment of the rudder relative to the hull, or by asymmetric shape of the rudder.

Some modifications were suggested as a consequence of the results of numerical simulations. First modification was to remove the rudder from the yacht and perform a precise measurement of the potential deviation from the ideal symmetric shape. This proposal proved to be as successful. It was found out that the deviation of the rudder shape was more than $5 \mathrm{~mm}$. The additional torque gained negligible values after modification of the rudder shape by special sealant.

Investigation of the influence of geometrical changes of the rudder to the additional torque can be done as a future work. There can be included the dependence of asymmetric shape of the rudder together with the overall size of the hull to the resultant additional torque. It could show how precise must be the production process of the rudders in relation to the overall size of the ship's hull and to the output of combustion engine respective to the ship's screw.

\section{Acknowledgment}

This research was financially supported under the project "Innovative fluid machines “, number: FSI-S-14-2480

\section{References}

1. Prandtl, L, Tietjens, O. Hydro- und Aeromechanics $I$. 238 p. S.I.: s.n., 1929

2. Prandtl, L, Tietjens, O. Fundamentals of Hydro- and aeromechanics. New York: Dover Publications, 2003, 280 p. ISBN 0486603741

3. Munson, Bruce Roy, Donald F Young a Theodore H Okiishi. Fundamentals of fluid mechanics. 5th. ed. Hoboken: Wiley, 2006, 770 s. ISBN 0-471-67582-2.

4. Huang, S, Xiang-Yuan, Z, Chun-Yu, G, Xin, Ch. CFD simulation of propeller and rudder performance when using additional thrust fins. Journal of Marine Science and Application. Online ISSN 1993-9433

5. Wu-Yoan K, Hye-Ryoun, Ch, CFD application for turbulent flow analysis around the sails and hull of a sailing yacht. Journal of Marine Science and Application. ISBN 978-1-880653-68-5

6. Wu-Yoan K, Jaehoon, Y, Zhengshou, Ch, Shin Hyung, R, Hye-Ryoun, Ch, Haeseong, A. Hydro- and aerodynamic analysis for the design of sailing yacht.
Journal of Marine Science and Application. Online ISSN 1437-8213

7. Scott, Thomas E. Power transmission: mechanical, hydraulic, pneumatic, and electrical. Upper Saddle River: Prentice Hall, c2000, xiii, 319 s. ISBN 0130953865.

8. Pletcher, Richard H, John C Tannehill, Dale A, Anderson. Computational fluid mechanics and heat transfer. 3rd ed. Boca Raton: CRC Press, c2013, xx, 753 s. ISBN 978-1-59169-037-5. 